\title{
Symposium review: Mechanisms linking metabolic stress with innate immunity in the endometrium ${ }^{1}$
}

\author{
I. Martin Sheldon, ${ }^{2}$ James G. Cronin, Mateusz Pospiech, and Matthew L. Turner \\ Swansea University Medical School, Swansea University, Swansea, SA2 8PP, United Kingdom
}

\section{ABSTRACT}

Bacterial infections of the uterus after parturition are ubiquitous in dairy cattle and often cause uterine disease, such as metritis or endometritis. However, the metabolic stress associated with milk production increases the risk of developing disease. Resolution of bacterial infections requires rapid and robust innate immune responses, which depend on host cell receptors recognizing pathogen-associated molecular patterns, such as lipopolysaccharide (LPS) from gram-negative bacteria. Here, we argue that metabolic stress impairs the inflammatory response to pathogens. Glucose and glutamine are the major energy sources for cells, but their abundance is reduced in postpartum dairy cows. Furthermore, inflammatory responses exacerbate metabolic stress, with animals and tissues consuming more glucose when challenged with LPS. However, depriving endometrial tissue of glucose or glutamine impairs the secretion of IL-1 $\beta$, IL- 6 , and IL- 8 in response to pathogen-associated molecular patterns. Glycolysis and the intracellular sensor of energy, AMP-activated protein kinase, are important for the response to LPS because perturbing glycolysis or AMP-activated protein kinase activity reduces the secretion of IL- $1 \beta$, IL- 6 , and IL- 8 in the endometrium. The mevalonate pathway for cellular cholesterol synthesis may also be linked to immunity, as inhibition of the terminal enzyme in the pathway, squalene synthase, reduces inflammatory responses to pathogenic bacteria and LPS. In contrast, only modest effects on inflammation are found when modulating the sensor of cellular nutrient satiety, mammalian target of rapamycin, or the endocrine regulator of metabolism, insulin-like growth factor-1. We suggest that stressing cellular metabolism increases the risk of uterine disease by impairing endometrial defenses.

Received May 9, 2017.

Accepted July 25, 2017.

${ }^{1}$ Presented as part of the Physiology and Endocrinology Symposium: Mediators of Effects of Stress on Reproduction, Growth, and Lactation at the ADSA Annual Meeting, Pittsburgh, Pennsylvania, June 2017.

${ }^{2}$ Corresponding author: i.m.sheldon@swansea.ac.uk
Key words: uterus, bacteria, inflammation, metabolism

\section{INTRODUCTION}

Bacterial infections of the uterus are ubiquitous after parturition in dairy cattle, often causing metritis and endometritis (Sheldon et al., 2009). Treating metritis, as well as the subsequent infertility and reduced milk production, costs the European Union and US dairy industries about $\$ 2$ billion/yr (Sheldon et al., 2009). The risk of developing uterine disease is increased by the metabolic stress associated with milk production (LeBlanc, 2012; Wathes, 2012; Esposito et al., 2014). Countering bacterial infections requires rapid and robust inflammatory responses, driven by the innate immune system (Sheldon et al., 2017). The systems of energy metabolism, innate immunity, and reproduction are highly integrated because they have co-evolved over millennia; thus, stress in one system may affect the others. Here, we argue that cellular metabolic stress impairs the inflammatory response to pathogens in the endometrium.

Many informative epidemiological and whole-animal studies have been carried out on the associations between dairy cow nutrition and disease, particularly in the transition period and early lactation. Reviewing the in vivo studies is beyond the scope of the present paper, and we refer readers to comprehensive reviews that encapsulate this information (Chagas et al., 2007; Sordillo et al., 2009; LeBlanc, 2012; Esposito et al., 2014). Here, we focus on tissue and cells, and review the mechanisms that may link cellular metabolic stress with innate immunity in the endometrium. Evidence is presented for the roles of glucose and glutamine in immunity, and how intracellular sensors of metabolism, hormones, and cholesterol may modulate cellular defense. We suggest that stressing cellular metabolism increases the risk of uterine disease by impairing endometrial defenses.

\section{METABOLIC STRESS}

The modern dairy cow is under metabolic stress because the energy demand of lactation is typically 3 
times the resting metabolic rate. For a typical dairy cow producing $40 \mathrm{~L}$ of milk/d, the metabolic energy requirements for milk production are about $200 \mathrm{MJ} / \mathrm{d}$, whereas only about $65 \mathrm{MJ} / \mathrm{d}$ is needed for maintenance. An equivalent metabolic demand for humans is running 3 marathons every day, because the energy expenditure to complete a marathon is almost the same as the runner's daily energy intake (Williams et al., 1984). Although dairy cattle have been genetically selected to produce milk, they simply cannot consume enough food to meet the metabolic demand of lactation. Consequently, body tissues are broken down to supply metabolic energy and satisfy the negative energy balance (LeBlanc, 2012; Wathes, 2012; Esposito et al., 2014). Negative energy balance is reflected by reduced blood concentrations of glucose, glutamine, and IGF-1 in postpartum animals (Doepel et al., 2006; Chagas et al., 2007; Wathes et al., 2011; Ingvartsen and Moyes, 2013). Furthermore, metabolic stress during early lactation in dairy cattle is associated with an increased incidence of uterine disease (Chagas et al., 2007; Kerestes et al., 2009; Galvão et al., 2010). Even more striking is that reduced appetite before calving increases the risk of severe uterine disease after parturition (Huzzey et al., 2007).

\section{UTERINE DISEASE AND INNATE IMMUNITY}

All cows have abundant bacteria in the uterine lumen after parturition (Sheldon et al., 2002). These bacteria come not only from the environment, but may also be part of a resident uterine microflora (Karstrup et al., 2017; Moore et al., 2017). However, high-milk yield cows have a propensity for developing bacterial disease of the endometrium. Up to $40 \%$ of animals develop metritis within $10 \mathrm{~d}$ of parturition, chronic endometritis persists $>3$ wk postpartum in about $20 \%$ of cows, and subclinical endometritis affects at least an additional $15 \%$ of animals (LeBlanc et al., 2002; Sheldon et al., 2002; Kasimanickam et al., 2004; Zwald et al., 2004; Sheldon et al., 2009). Based on culture and molecular techniques, key bacteria in the pathogenesis of postpartum uterine disease include endometrial pathogenic Escherichia coli, Trueperella pyogenes, and anaerobic bacteria, such as Fusobacteria, Prevotella, and Bacteroides species (Noakes et al., 1991; Sheldon et al., 2002; Sheldon et al., 2010; Amos et al., 2014; Bicalho et al., 2017).

Bacteria are sensed by the innate immune system, with their pathogen-associated molecular patterns detected by pattern recognition receptors, such as Toll-like receptors (TLR) on endometrial cells, neutrophils, and macrophages (reviewed in: Sheldon et al., 2017). For example, TLR4 binds the LPS endotoxin of E. coli, and TLR2, TLR1, and TLR6 bind bacterial lipopeptides. Activation of TLR signaling in endometrial cells leads to the secretion of prostaglandins and IL- $1 \beta$, IL- 6 , and IL-8 (Herath et al., 2006; Herath et al., 2009; Cronin et al., 2012; Turner et al., 2014); however, the response to pathogen molecules is energetically expensive in vivo and in vitro (Turner et al., 2016; Kvidera et al., 2017). A striking example is that animals require an additional kilogram of glucose to supply the activated immune system in the first $12 \mathrm{~h}$ after in vivo challenge with LPS (Kvidera et al., 2017). Unfortunately, uterine disease further exacerbates metabolic stress because cows with metritis eat $2 \mathrm{~kg} / \mathrm{d}$ less food (Wittrock et al., 2011). Metabolic interactions also occur between host and pathogens because tissues and bacteria compete for the same nutrients, and pathogens can sense and adapt to metabolic changes in tissues (Olive and Sassetti, 2016).

Rapid and robust inflammatory responses are important to resist bacterial infections effectively and return animals to health (Medzhitov, 2008; Chovatiya and Medzhitov, 2014; Sheldon et al., 2017). Delayed or inadequate acute inflammatory responses can lead to problems, including failure to clear microbes, disrupting the active resolution of inflammation, and delaying the repair of inflamed and damaged tissues. Missing the opportunity to counter infections effectively often leads to chronic inflammation (Figure 1). Indeed, chronic endometritis is a common sequel to postpartum uterine infections in dairy cows (Chagas et al., 2007; Kerestes et al., 2009; Sheldon et al., 2009; LeBlanc, 2012). Furthermore, animals manipulated to have severe negative energy balance had increased abundance of inflammatory genes in the endometrium 2 wk postpartum, whereas animals in mild negative energy balance appeared to have recovered by that time (Wathes et al., 2009; Wathes, 2012).

Innate immunity is optimally tuned when metabolism is in homeostatic balance (Chovatiya and Medzhitov, 2014; O'Neill et al., 2016). Thus, compromised function of peripheral blood neutrophils may be one explanation for how negative energy balance is linked to uterine disease (Hammon et al., 2006; Galvão et al., 2010; LeBlanc, 2012; Mendonça et al., 2013). However, nutrient availability often has subtle effects on circulating immune cells and considerable variation exists among studies. Furthermore, we reason that the persistence of neutrophils may reflect a failure in the innate immune system to return the postpartum endometrium to homeostasis. Our alternative concept is that stressing cellular metabolism increases the risk of disease by impairing defenses in the tissue and cells of the endometrium. 


\section{GLUCOSE AND GLUTAMINE}

Glucose and glutamine are the major carbon substrates used by most cells for metabolic energy (Wellen et al., 2010; O'Neill et al., 2016). Glycolysis and the Krebs cycle yield NADH and ATP from glucose (Figure 2). Glutamine is anapleurotic; supplying substrate for the Krebs cycle following glutaminolysis to glutamate, and converting glutamate to $\alpha$-ketoglutarate (DeBerardinis and Cheng, 2010; Zhang et al., 2017). During innate immune responses to LPS, macrophages and monocytes further increase the supply of ATP and anabolic substrates by accelerating glucose flux to lactate via aerobic glycolysis, which is often called the Warburg effect (Tannahill et al., 2013; Turner et al., 2016). In the endometrium, the response to LPS is similarly energetically expensive, with endometrial tissue and cell cultures consuming additional glucose

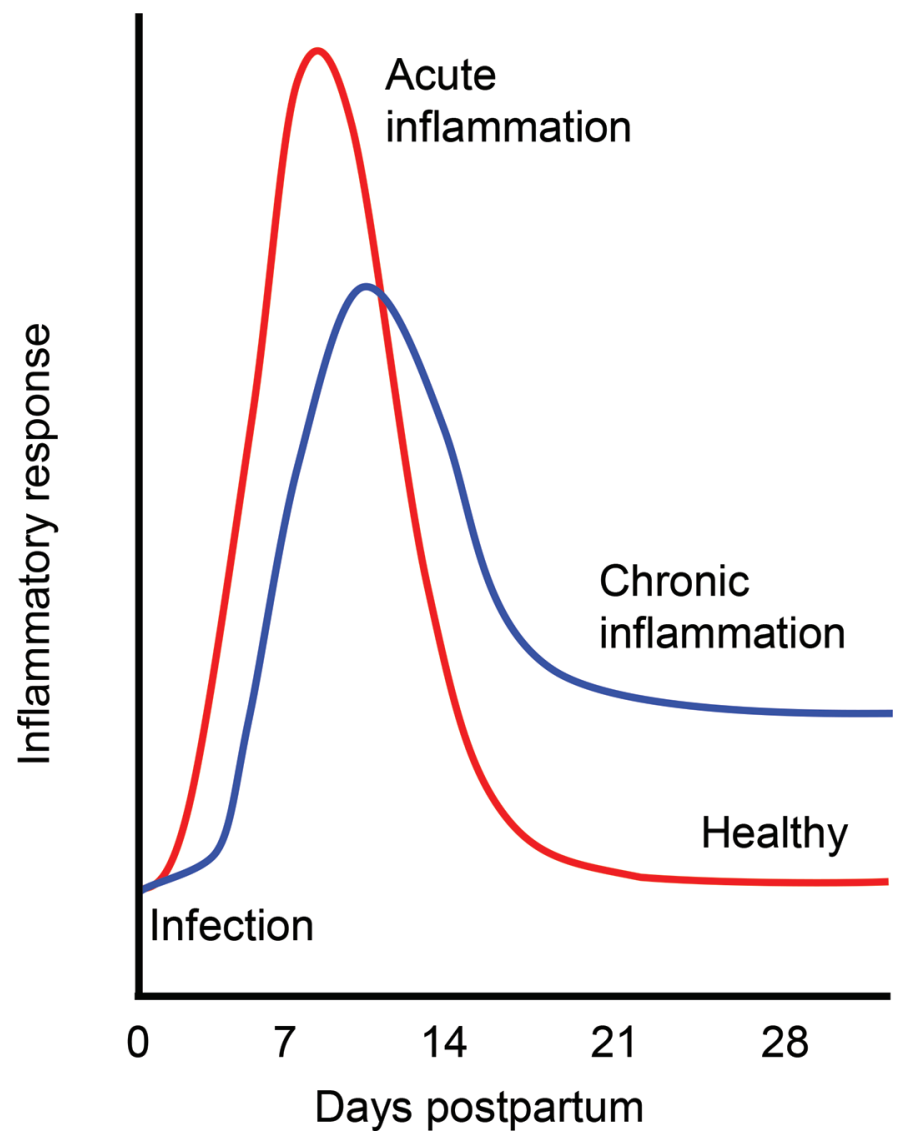

Figure 1. Progression of inflammation during bacterial infection. Rapid and robust acute inflammatory responses [gray (red) line] are important to resist bacterial infections effectively. Once the infection is controlled, there is a return to homeostasis by active resolution of inflammation and repair of damaged tissues. Delayed or inadequate inflammatory responses may not fully resolve infections [black (blue) line], leading to chronic inflammation. Color version available online.

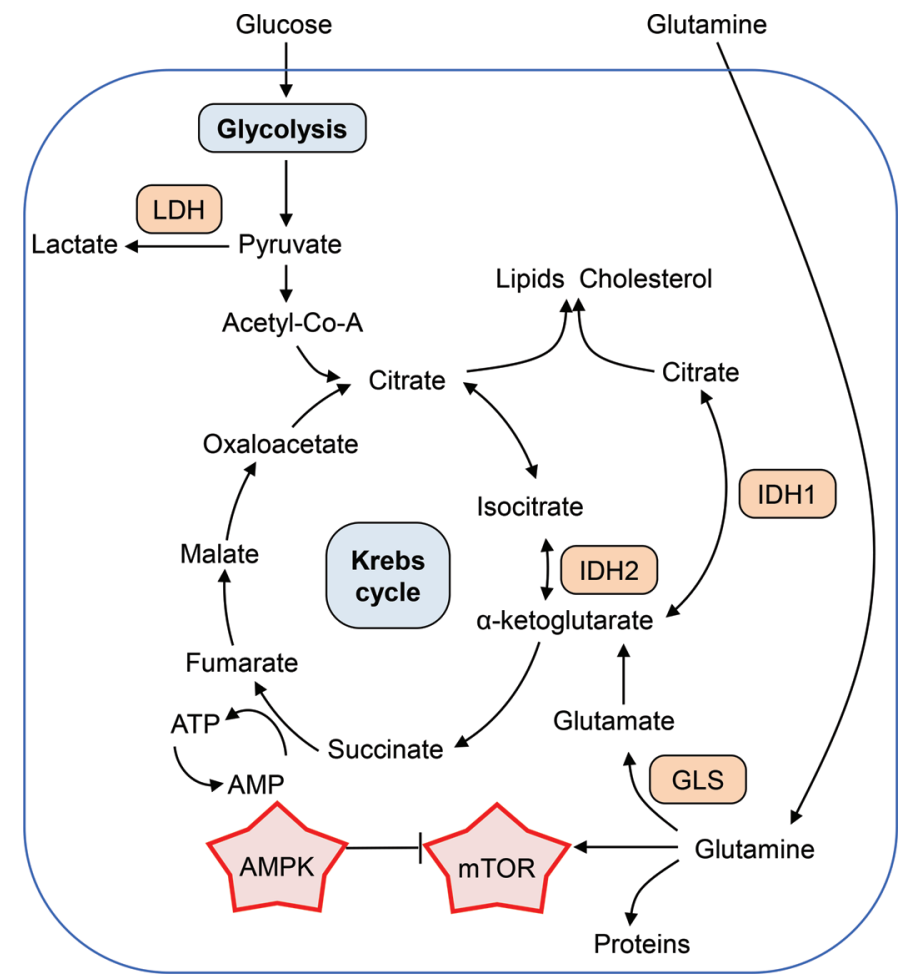

Figure 2. Cellular energy metabolism. Most ATP for cellular energy is generated by glucose flux through glycolysis into the Krebs cycle, followed by oxidative phosphorylation in mitochondria. Infections also induce the Warburg effect, with increased glucose flux through glycolysis and conversion of pyruvate to lactate by lactate dehydrogenase $(\mathrm{LDH})$, leading to the rapid generation of ATP and substrates for membranes, nucleotides, and proteins. Glutamine also contributes to ATP production by entering the Krebs cycle after glutaminolysis by glutaminase (GLS) and conversion to $\alpha$-ketoglutarate. As well as entering the Krebs cycle, $\alpha$-ketoglutarate can be converted to citrate in mitochondria and the cytoplasm by isocitrate dehydrogenase (IDH), and citrate contributes to lipid synthesis. The intracellular sensors AMP-activated protein kinase (AMPK) and mammalian target of rapamycin (mTOR) regulate cellular metabolism. Color version available online.

and inducing the Warburg effect (Turner et al., 2016). However, in postpartum dairy cows under metabolic stress, the abundance of glucose and glutamine is often reduced in the peripheral circulation (Doepel et al., 2006; Ingvartsen and Moyes, 2013). Furthermore, it is the local abundance of glucose and glutamine in the endometrial tissue that is important, and this may be further reduced in damaged tissues after parturition.

Exciting evidence is emerging for integration of metabolism with innate immunity in immune cells, including dendritic cells and macrophages (Krawczyk et al., 2010; Tannahill et al., 2013; O'Neill et al., 2016). Our recent studies using bovine endometrium also examined the effect of glucose and glutamine abundance on innate immunity (Figure 3; Turner et al., 2016; Noleto et al., 2017). Limiting the availability of glucose to ex vivo 
organ cultures of endometrium reduces the secretion of IL-1 $\beta$, IL-6, and IL-8 in response to LPS or lipopeptides (Turner et al., 2016). Similarly, depletion of glutamine, in the presence of abundant glucose, reduced the IL$1 \beta$, IL-6, and IL-8 response to LPS by at least $50 \%$ (Noleto et al., 2017). A key finding in these studies was that the abundance of glucose and glutamine were more important for inflammatory responses than their absolute concentrations. The availability of glucose and glutamine to cells depends on several transmembrane glucose and glutamine transporters, which are regulated by intracellular regulators of metabolism (Zoncu et al., 2011; Hardie et al., 2012). Nutrient transporters are also regulated by several hormones such as insulin and IGF-1; although, dairy cows are often insulin-resistant after partition (Kerestes et al., 2009; De Koster and Opsomer, 2013; Forde et al., 2014). Exploring the effect of the abundance of nutrients, rather than nutrient concentrations, is a conceptual change because most dairy cow studies focus on monitoring or mimicking
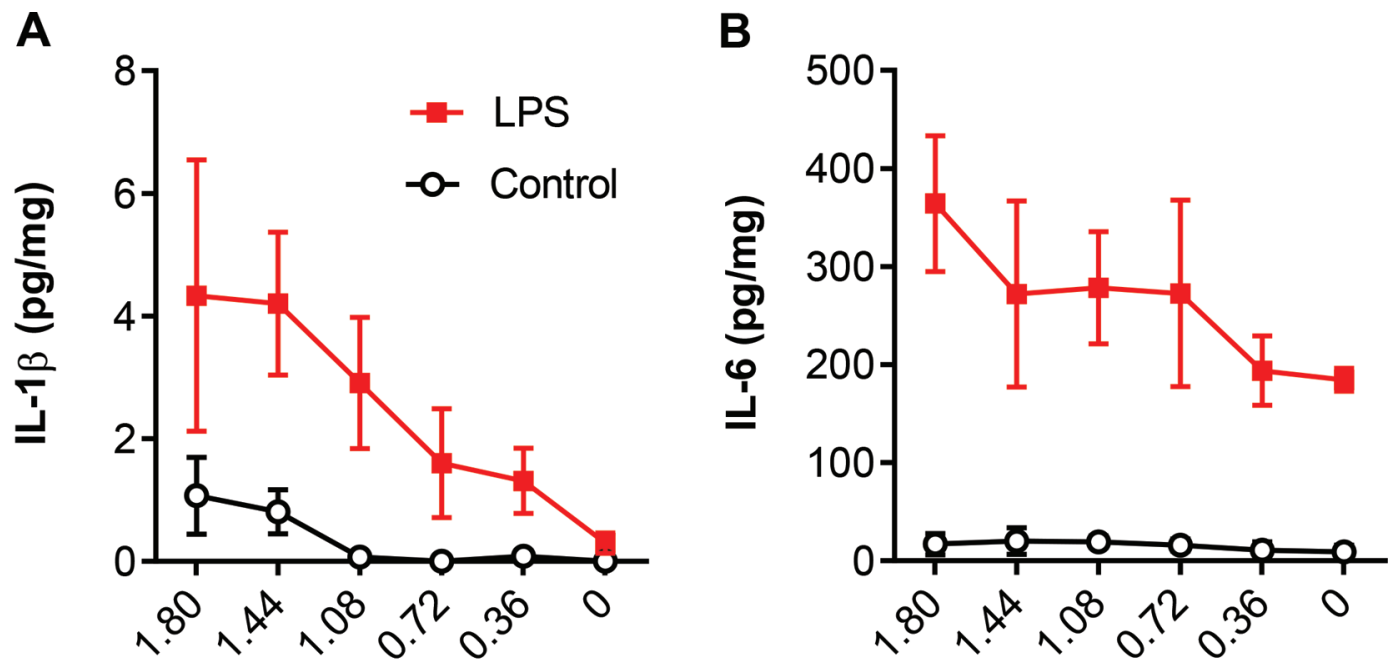

\section{Glucose (mg/organ)}

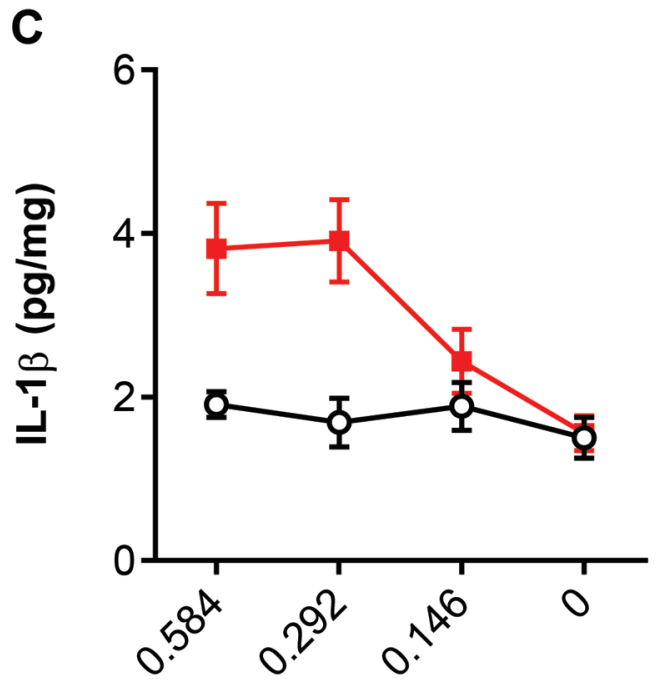

Glutamine (mg/organ)

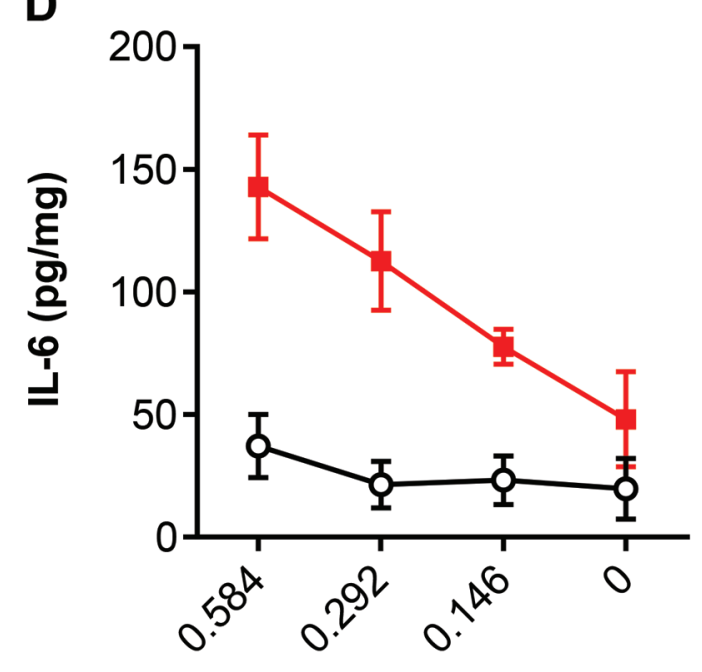

Glutamine (mg/organ)

Figure 3. Glucose and glutamine availability modulates inflammation in endometrial tissue. Ex vivo organ cultures of bovine endometrium were cultured for $24 \mathrm{~h}$ in media containing a range of amounts of glucose $(\mathrm{A}, \mathrm{B})$ or glutamine $(\mathrm{C}, \mathrm{D})$, and then challenged with control vehicle $(\bigcirc)$ or $100 \mathrm{ng} / \mathrm{mL}$ of LPS $(\square)$ for a further $24 \mathrm{~h}$. Limiting the abundance of glucose or glutamine reduced $(P<0.05$, ANOVA) the accumulation of the proinflammatory cytokines IL-1 $\beta$ (A, C) and IL-6 (B, D) in response to LPS. Graphs were redrawn from Turner et al. (2016) and Noleto et al. (2017) and present mean \pm SEM concentration per milligram of endometrial tissue. Color version available online. 
blood concentrations of nutrients. However, we propose that immune responses depend on the abundance of nutrients entering into the cells of the postpartum endometrium and their flux through the cellular metabolic pathways.

As might be expected, in the absence of both glucose and glutamine endometrial inflammatory responses to LPS are markedly reduced (Noleto et al., 2017); however, supplying glucose alone increased inflammation, whereas supplying glutamine alone did not. The dependence of glutamine metabolism on glycolysis was confirmed using 2-deoxy-D-glucose to inhibit glycolysis, which prevented inflammatory responses to LPS in endometrial organ cultures (Noleto et al., 2017). Similar observations of the importance of glycolysis to facilitate glutamine utilization for cellular energy have been reported in several mammalian cells (Wellen et al., 2010). Together, the evidence implies that effective innate immune responses in the endometrium depend on glucose availability, glycolysis, and glutamine abundance.

\section{INTRACELLULAR REGULATORS OF METABOLISM}

As well as the dependence on the abundance of nutrients, cellular energy homeostasis is regulated by hormones and intracellular regulatory pathways. The major intracellular sensors of metabolic sufficiency are AMP-activated protein kinase (AMPK) and mammalian target of rapamycin (mTOR; Hotamisligil and Erbay, 2008; Zoncu et al., 2011; Hardie et al., 2012). The principal regulator of cellular energy is AMPK, which senses the ratio of AMP:ATP in the cytosol (Figure 2). In addition to the metabolic energy required for lactation, demands on cellular energy to counter infections and repair tissues increase the ratio of AMP: ATP, leading to activation of AMPK by phosphorylation (Hardie et al., 2012). Activated AMPK restores energy balance by inhibiting anabolic pathways that use ATP while stimulating glycolysis, mitochondrial biogenesis, and increasing the expression of glucose and glutamine transporters. Mammalian target of rapamycin is a less-specific sensor of cellular energy status than AMPK. The 2 main multiprotein mTOR complexes (mTORC1 and mTORC2) integrate multiple signals of satiety from amino acid abundance, growth factors, hormones, and AMPK (Zoncu et al., 2011; Saxton and Sabatini, 2017). When nutrients are abundant, activation of mTOR stimulates anabolic pathways and cell growth; however, when cellular energy is limited, phosphorylated AMPK inhibits mTOR to conserve energy and limit protein synthesis.

Activating AMPK in endometrial organ cultures, using 5-aminoimidazole-4-carboxamide ribonucleotide to mimic an energy deficit, reduced the secretion of IL-1 $\beta$, IL-6 (Figure 4A), and IL-8 in response to LPS by at least $50 \%$, even in the presence of abundant glucose and glutamine (Turner et al., 2016). Surprisingly, inhibiting AMPK with compound $\mathrm{C}$ also reduced endometrial organ culture inflammatory responses to LPS (Turner et al., 2016). We interpreted these data to postulate that a homeostatic level of AMPK activation fosters optimal inflammatory responses.
A

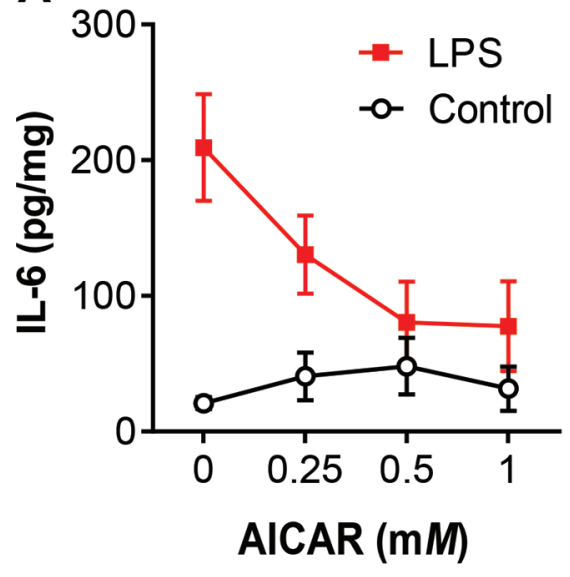

B

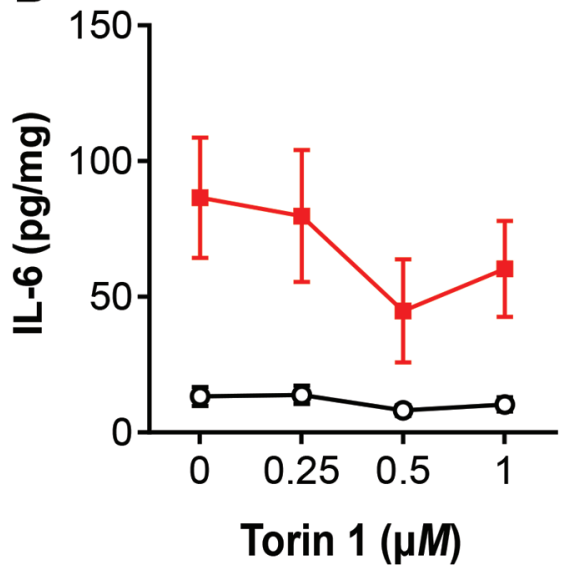

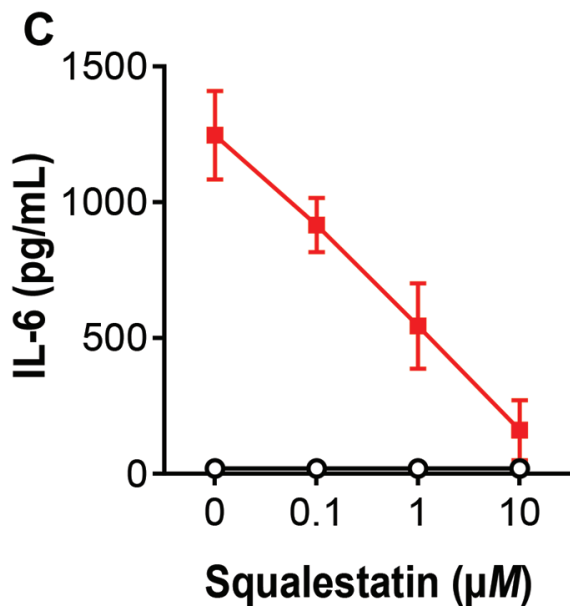

Figure 4. Metabolic regulators in cells affect inflammation. Ex vivo organ cultures of endometrium were cultured for 24 h in medium containing the indicated amounts of (A) AICAR (5-aminoimidazole-4-carboxamide ribonucleotide) to activate AMP-activated protein kinase, or (B) Torin 1 to inhibit mammalian target of rapamycin. (C) Bovine endometrial stromal cells were cultured for $24 \mathrm{~h}$ in medium containing the indicated amounts of squalestatin to inhibit squalene synthase. Cultures were then treated with control vehicle (O) or 100 ng/mL of LPS ( $\mathbf{\square})$ for a further $24 \mathrm{~h}$. Each of the compounds reduced $(P<0.05$, ANOVA) the accumulation of IL-6 in response to LPS. Graphs are redrawn from Turner et al. (2016) and Healey et al. (2016; https://creativecommons.org/licenses/by/3.0/), and present mean \pm SEM concentrations per milligram of endometrial tissue $(\mathrm{A}, \mathrm{B})$, or per milliliter of culture supernatant (C). Color version available online. 
In contrast to manipulation of AMPK, inhibition of mTOR to mimic cellular energy deficits had less effect on innate immunity. The mTOR inhibitor rapamycin had no significant effect on endometrial organ culture responses to LPS, whereas the inhibitor Torin-1 gave a modest reduction in the secretion of IL-1 $\beta$, IL-6 (Figure 4B), and IL-8 (Turner et al., 2016). One explanation for these apparent discrepancies is that rapamycin inhibits mTORC1, whereas Torin 1 inhibits mTORC1 and mTORC2 (Zoncu et al., 2011; Saxton and Sabatini, 2017). Although mTORC2 may have a role in endometrial tissue under the conditions tested, the data provide evidence that AMPK is an important link between cellular metabolic stress and innate immunity in the endometrium.

\section{HORMONES}

The pregnant cow has high peripheral plasma concentrations of progesterone and estradiol, which fall to basal levels after parturition, and postpartum dairy cows are often insulin-resistant and have lower plasma concentrations of IGF-1 (Beam and Butler, 1999; Wathes et al., 2009; LeBlanc, 2012; Wathes, 2012; Wathes et al., 2012; De Koster and Opsomer, 2013; Esposito et al., 2014). Metabolic stress in postpartum dairy cows can also limit LH pulse frequency, perturb the return of ovarian follicle activity, and delay ovulation (Beam and Butler, 1999). The effect of ovarian steroid hormones on postpartum uterine function is not clear. Progesterone is considered immuno-suppressive, whereas estradiol may enhance immunity and was used to treat uterine disease (Lewis, 2003). However, conflicting data exist, and exogenous estradiol infused into the bovine uterus during the postpartum period increased the abundance of bacteria in the uterus (Sheldon et al., 2004). Furthermore, the stage of the estrous cycle, or exogenous progesterone or estradiol, did not modulate innate immunity in ex vivo organ cultures of bovine endometrium (Saut et al., 2014). Similarly, treatment with estradiol or progesterone, or inhibitors of estradiol or progesterone nuclear receptors, did not affect gene or protein expression for IL-1 $\beta$, IL-6, or IL-8 in endometrial cells or macrophages (Saut et al., 2014).

Apart from ovarian steroid hormones, the metabolic hormones insulin and IGF-1 are obvious candidates that might link postpartum metabolic stress and immunity, as concentrations of IGF-1 are reduced and animals are often insulin-resistant (Wathes et al., 2011; De Koster and Opsomer, 2013). Furthermore, IGFbinding proteins and receptors have been characterized in the postpartum uterus, with differential expression between the previously gravid and non-gravid horns (Llewellyn et al., 2008; Wathes, 2012). However, ma- nipulating the concentration of exogenous IGF-1 did not affect the inflammatory response to LPS in ex vivo organ cultures of bovine endometrium (Turner et al., 2016). Other potential endocrine regulators of immunity for animals under postpartum stress might include growth hormone, leptin, prolactin, glucagon, ghrelin, prostaglandins, and cortisol. Interestingly, cows that developed metritis had increased cortisol at parturition compared with animals that had subclinical endometritis (Galvão et al., 2010). Furthermore, dexamethasone consistently reduces inflammatory responses to LPS in the endometrium and in immune cells (Saut et al., 2014). Whereas multiple hormones are important at the level of the whole animal, the molecular detail of how they affect tissue defenses is not yet clear.

\section{CHOLESTEROL}

When dairy cows mobilize adipose tissue to satisfy the negative energy balance of lactation, there is an increased peripheral plasma concentration of nonesterified fatty acids (Sordillo et al., 2009; Wathes et al., 2012). These fatty acids are metabolized in tissues to acetyl CoA to provide cellular energy, although excess fatty acid oxidation leads to increased production of ketones. During an immune response, tissue cells tend to further exploit fatty acid oxidation to supply nutrients, whereas immune cells exposed to pathogens often increase fatty acid synthesis as part of their inflammatory response (O'Neill et al., 2016). However, apart from cholesterol, limited information exists about the mechanistic cross-talk between lipids and immunity in the bovine endometrium.

Most of the cholesterol in cells is contained within the plasma membrane, and the concentrations of this lipid are tightly regulated by cholesterol uptake, cholesterol efflux transporters, and by cholesterol synthesis (Goldstein and Brown, 1990). The first steps in cholesterol synthesis are encompassed by the mevalonate pathway, converting acetyl-CoA to isoprenoids, which are then converted to squalene, and ultimately to cholesterol (Figure 5). Cholesterol is partially responsible for the fluidity of plasma membranes and, as TLR often dimerize within cholesterol-rich lipid rafts in membranes, changes in cellular cholesterol can affect innate immunity (Dykstra et al., 2003). Intriguingly, lower cholesterol concentrations in postpartum dairy cattle are also associated with uterine disease (Sepúlveda-Varas et al., 2015).

To examine if the mevalonate pathway affects innate immunity, chemical inhibitors and small interfering RNA were used to target the mevalonate pathway enzymes, 3-hydroxy-3-methyl-glutaryl-coenzyme A reductase, farnesyl diphosphate synthase, and squalene 


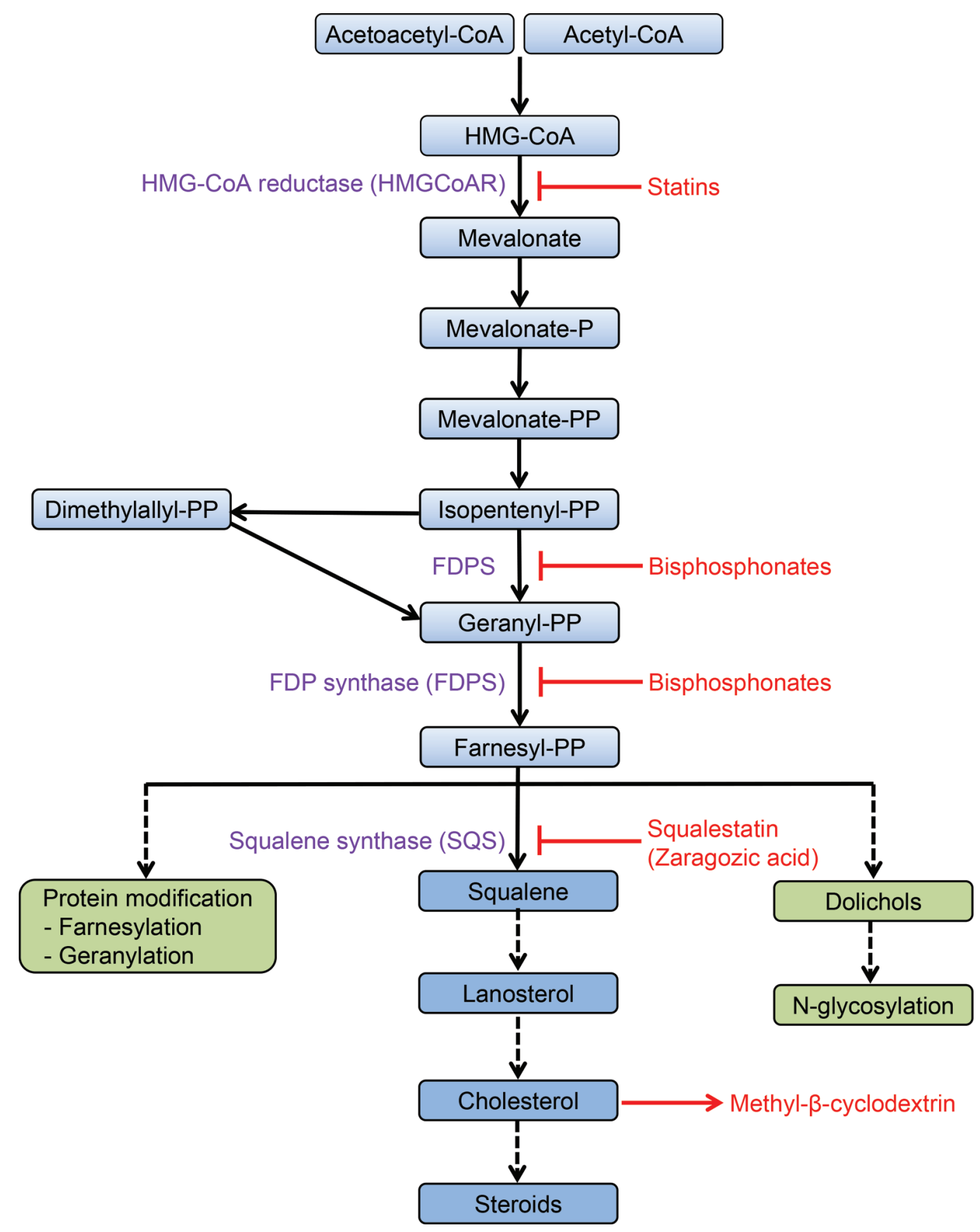

Figure 5. The mevalonate pathway and cholesterol synthesis. Acetyl CoA and acetoacetyl CoA are converted via the isoprenoids to squalene, which is subsequently converted to cholesterol. The key enzymes in the mevalonate pathway are 3-hydroxy-3-methyl-glutaryl-coenzyme A reductase (HMGCoAR), farnesyl diphosphate synthase (FDPS), and squalene synthase (SQS). Each of these enzymes can be inhibited by statins, bisphosphonates, and squalestatin, respectively; and cellular cholesterol can be depleted using methyl- $\beta$-cyclodextrin. PP $=$ diphosphate. Color version available online.

synthase, which is also known as farnesyl-diphosphate farnesyltransferase 1 (Figure 5). Whereas inhibiting 3-hydroxy-3-methyl-glutaryl-coenzyme A reductase or farnesyl diphosphate synthase had little effect on inflammation, inhibiting squalene synthase reduced
IL- 6 and IL- 8 secretion in response to live $E$. coli or T. pyogenes, or LPS in endometrial tissue, and to LPS in epithelial and stromal cells (Figure 4C) (Healey et al., 2016). As inhibition of squalene synthase might increase the abundance of the farnesyl and geranyl 
isoprenoids and reduce the concentration of cholesterol (Figure 5), these indirect effects were also examined (Healey et al., 2016). Although depletion of cholesterol with methyl- $\beta$ cyclodextrin had no significant effect, treating endometrial cells with isoprenoids reduced interleukin secretion. These results provide evidence that the mevalonate pathway, and particularly inhibition of squalene synthase, can modulate innate immunity in the endometrium.

A discussion of the role of cholesterol in endometritis is incomplete without mentioning cellular resilience, because many bacteria secrete pore-forming toxins that target cholesterol in plasma membranes. In particular, T. pyogenes secretes pyolysin (PLO), which is a cholesterol-dependent cytolysin, and a key virulence factor associated with uterine disease in dairy cattle. Interestingly, PLO does not stimulate an inflammatory response, but $T$. pyogenes does lead to inflammation, presumably via TLR2 on endometrial cells recognizing bacterial lipopeptides (Borges et al., 2012; Turner et al., 2014). However, PLO causes considerable pathology by binding cholesterol-rich domains in the plasma membrane of endometrial cells and forming pores that lead to osmotic cell death (Amos et al., 2014; Preta et al., 2015). Endometrial stromal cells have abundant cholesterol and are particularly sensitive to PLO, which may explain how $T$. pyogenes switches from a commensal bacterium when the epithelium is intact to cause uterine pathology once the epithelium is breached during and after parturition, allowing bacteria to access the stroma (Amos et al., 2014). Reducing cellular cholesterol, using methyl- $\beta$-cyclodextrin or an endocytosis inhibitor, increases the resilience of stromal cells to PLO (Amos et al., 2014; Preta et al., 2015). Taking the observations together, reducing cellular cholesterol may limit inflammation but increase stromal cell resilience to pore-forming toxins.

\section{CONCLUSIONS}

The present review starts with the premise that metabolic stress, particularly negative energy balance, is associated with postpartum metritis and endometritis. Resisting bacterial infections depends on the prompt detection of pathogens by the innate immune system, followed by rapid and robust inflammatory responses. Here, we focused on mechanisms in endometrial tissues and cells. We described several mechanisms where cellular metabolic stress may limit the necessary acute inflammatory response and the prompt resolution of bacterial infections. The strongest links between metabolism and immunity appear to reflect the coevolution of cellular metabolism and innate immunity. In particular, inflammatory responses are dependent on the abundance of glucose and glutamine for cellular energy, and the role of AMPK, which is the principal sensor of ATP sufficiency. Whereas, the more generalized regulators of cell metabolism, including mTOR and IGF-1, appear to have a lesser effect on inflammation. The interrelationship between disease and metabolism are highly complex, as illustrated by cholesterol homeostasis, which can affect both innate immune responses to pathogen-associated molecules and cellular resilience to pore-forming toxins. The system in vivo is even more complex, and insights from the endometrium are only a small part of the whole story. However, consistent among the evidence for links between cellular metabolism and immunity is that metabolic homeostasis fosters optimal inflammatory responses to resist pathogens. We suggest that stressing cellular metabolism increases the risk of uterine disease by impairing endometrial defenses.

\section{ACKNOWLEDGMENTS}

Work in the Sheldon laboratory was funded by the Biotechnology and Biological Sciences Research Council (Swindon, UK; BB/I017240/1; BB/K006592/1).

\section{REFERENCES}

Amos, M. R., G. D. Healey, R. J. Goldstone, S. Mahan, A. Duvel, H. J. Schuberth, O. Sandra, P. Zieger, I. Dieuzy-Labaye, D. G. E. Smith, and I. M. Sheldon. 2014. Differential endometrial cell sensitivity to a cholesterol-dependent cytolysin links Trueperella pyogenes to uterine disease in cattle. Biol. Reprod. 90:54. https:// doi.org/10.1095/biolreprod.113.115972.

Beam, S. W., and W. R. Butler. 1999. Effects of energy balance on follicular development and first ovulation in postpartum dairy cows. J. Reprod. Fertil. Suppl. 54:411-424.

Bicalho, M. L. S., S. Lima, C. H. Higgins, V. S. Machado, F. S. Lima, and R. C. Bicalho. 2017. Genetic and functional analysis of the bovine uterine microbiota. Part II: Purulent vaginal discharge versus healthy cows. J. Dairy Sci. 100:3863-3874. https://doi.org/10 .3168/jds.2016-12061.

Borges, A. M., G. D. Healey, and I. M. Sheldon. 2012. Explants of intact endometrium to model bovine innate immunity and inflammation ex vivo. Am. J. Reprod. Immunol. 67:526-539. https://doi $.0 r g / 10.1111 / \mathrm{j} .1600-0897.2012 .01106 . x$.

Chagas, L. M., J. J. Bass, D. Blache, C. R. Burke, J. K. Kay, D. R. Lindsay, M. C. Lucy, G. B. Martin, S. Meier, F. M. Rhodes, J. R. Roche, W. W. Thatcher, and R. Webb. 2007. Invited review: New perspectives on the roles of nutrition and metabolic priorities in the subfertility of high-producing dairy cows. J. Dairy Sci. 90:4022-4032. https://doi.org/10.3168/jds.2006-852.

Chovatiya, R., and R. Medzhitov. 2014. Stress, inflammation, and defense of homeostasis. Mol. Cell 54:281-288. https://doi.org/10 .1016/j.molcel.2014.03.030.

Cronin, J. G., M. L. Turner, L. Goetze, C. E. Bryant, and I. M. Sheldon. 2012. Toll-Like receptor 4 and MyD88-dependent signaling mechanisms of the innate immune system are essential for the response to lipopolysaccharide by epithelial and stromal cells of the bovine endometrium. Biol. Reprod. 86:51-59. https://doi.org/ 10.1095/biolreprod.111.092718

De Koster, J. D., and G. Opsomer. 2013. Insulin resistance in dairy cows. Vet. Clin. North Am. Food Anim. Pract. 29:299-322. https://doi.org/10.1016/j.cvfa.2013.04.002. 
DeBerardinis, R. J., and T. Cheng. 2010. Q's next: the diverse functions of glutamine in metabolism, cell biology and cancer. Oncogene 29:313-324. https://doi.org/10.1038/onc.2009.358.

Doepel, L., M. Lessard, N. Gagnon, G. E. Lobley, J. F. Bernier, P. Dubreuil, and H. Lapierre. 2006. Effect of postruminal glutamine supplementation on immune response and milk production in dairy cows. J. Dairy Sci. 89:3107-3121. https://doi.org/10.3168/ jds.S0022-0302(06)72585-1.

Dykstra, M., A. Cherukuri, H. W. Sohn, S. J. Tzeng, and S. K. Pierce. 2003. Location is everything: lipid rafts and immune cell signaling. Annu. Rev. Immunol. 21:457-481. https://doi.org/10.1146/ annurev.immunol.21.120601.141021.

Esposito, G., P. C. Irons, E. C. Webb, and A. Chapwanya. 2014. Interactions between negative energy balance, metabolic diseases, uterine health and immune response in transition dairy cows. Anim. Reprod. Sci. 144:60-71. https://doi.org/10.1016/j.anireprosci.2013 .11.007.

Forde, N., C. A. Simintiras, R. Sturmey, S. Mamo, A. K. Kelly, T. E. Spencer, F. W. Bazer, and P. Lonergan. 2014. Amino acids in the uterine luminal fluid reflects the temporal changes in transporter expression in the endometrium and conceptus during early pregnancy in cattle. PLoS One 9:e100010. https://doi.org/10.1371/ journal.pone.0100010.

Galvão, K. N., M. J. Flaminio, S. B. Brittin, R. Sper, M. Fraga, L. Caixeta, A. Ricci, C. L. Guard, W. R. Butler, and R. O. Gilbert. 2010. Association between uterine disease and indicators of neutrophil and systemic energy status in lactating Holstein cows. J. Dairy Sci. 93:2926-2937. https://doi.org/10.3168/jds.2009-2551.

Goldstein, J. L., and M. S. Brown. 1990. Regulation of the mevalonate pathway. Nature 343:425-430. https://doi.org/10.1038/343425a0.

Hammon, D. S., I. M. Evjen, T. R. Dhiman, J. P. Goff, and J. L. Walters. 2006. Neutrophil function and energy status in Holstein cows with uterine health disorders. Vet. Immunol. Immunopathol. 113:21-29. https://doi.org/10.1016/j.vetimm.2006.03.022.

Hardie, D. G., F. A. Ross, and S. A. Hawley. 2012. AMPK: A nutrient and energy sensor that maintains energy homeostasis. Nat. Rev. Mol. Cell Biol. 13:251-262. https://doi.org/10.1038/nrm3311.

Healey, G. D., C. Collier, S. Griffin, H. J. Schuberth, O. Sandra, D. G. Smith, S. Mahan, I. Dieuzy-Labaye, and I. M. Sheldon. 2016. Mevalonate biosynthesis intermediates are key regulators of innate immunity in bovine endometritis. J. Immunol. 196:823-831. https://doi.org/10.4049/jimmunol.1501080.

Herath, S., D. P. Fischer, D. Werling, E. J. Williams, S. T. Lilly, H. Dobson, C. E. Bryant, and I. M. Sheldon. 2006. Expression and function of Toll-like receptor 4 in the endometrial cells of the uterus. Endocrinology 147:562-570. https://doi.org/10.1210/ en.2005-1113.

Herath, S., S. T. Lilly, D. P. Fischer, E. J. Williams, H. Dobson, C. E. Bryant, and I. M. Sheldon. 2009. Bacterial lipopolysaccharide induces an endocrine switch from prostaglandin $\mathrm{F}_{2 \mathrm{a}}$ to prostaglandin $\mathrm{E}_{2}$ in bovine endometrium. Endocrinology 150:1912-1920.

Hotamisligil, G. S., and E. Erbay. 2008. Nutrient sensing and inflammation in metabolic diseases. Nat. Rev. Immunol. 8:923-934. https://doi.org/10.1038/nri2449.

Huzzey, J. M., D. M. Veira, D. M. Weary, and M. A. von Keyserlingk. 2007. Prepartum behavior and dry matter intake identify dairy cows at risk for metritis. J. Dairy Sci. 90:3220-3233. https://doi .org/10.3168/jds.2006-807.

Ingvartsen, K. L., and K. Moyes. 2013. Nutrition, immune function and health of dairy cattle. Animal 7(Suppl. 1):112-122. https:// doi.org/10.1017/S175173111200170X.

Karstrup, C. C., K. Klitgaard, T. K. Jensen, J. S. Agerholm, and H. G. Pedersen. 2017. Presence of bacteria in the endometrium and placentomes of pregnant cows. Theriogenology 99:41-47. https:// doi.org/10.1016/j.theriogenology.2017.05.013.

Kasimanickam, R., T. F. Duffield, R. A. Foster, C. J. Gartley, K. E. Leslie, J. S. Walton, and W. H. Johnson. 2004. Endometrial cytology and ultrasonography for the detection of subclinical endometritis in postpartum dairy cows. Theriogenology 62:9-23.

Kerestes, M., V. Faigl, M. Kulcsar, O. Balogh, J. Foldi, H. Febel, Y. Chilliard, and G. Huszenicza. 2009. Periparturient insulin secre- tion and whole-body insulin responsiveness in dairy cows showing various forms of ketone pattern with or without puerperal metritis. Domest. Anim. Endocrinol. 37:250-261. https://doi.org/10.1016/j .domaniend.2009.07.003.

Krawczyk, C. M., T. Holowka, J. Sun, J. Blagih, E. Amiel, R. J. DeBerardinis, J. R. Cross, E. Jung, C. B. Thompson, R. G. Jones, and E. J. Pearce. 2010. Toll-like receptor-induced changes in glycolytic metabolism regulate dendritic cell activation. Blood 115:47424749. https://doi.org/10.1182/blood-2009-10-249540.

Kvidera, S. K., E. A. Horst, M. Abuajamieh, E. J. Mayorga, M. V. Fernandez, and L. H. Baumgard. 2017. Glucose requirements of an activated immune system in lactating Holstein cows. J. Dairy Sci. 100:2360-2374. https://doi.org/10.3168/jds.2016-12001.

LeBlanc, S. J. 2012. Interactions of metabolism, inflammation, and reproductive tract health in the postpartum period in dairy cattle. Reprod. Domest. Anim. 47(Suppl 5):18-30. https://doi.org/10 .1111/j.1439-0531.2012.02109.x.

LeBlanc, S. J., T. F. Duffield, K. E. Leslie, K. G. Bateman, G. P. Keefe, J. S. Walton, and W. H. Johnson. 2002. Defining and diagnosing postpartum clinical endometritis and its impact on reproductive performance in dairy cows. J. Dairy Sci. 85:2223-2236.

Lewis, G. S. 2003. Steroidal regulation of uterine resistance to bacterial infection in livestock. Reprod. Biol. Endocrinol. 1:117. https:// doi.org/10.1186/1477-7827-1-117.

Llewellyn, S., R. Fitzpatrick, D. A. Kenny, J. Patton, and D. C. Wathes. 2008. Endometrial expression of the insulin-like growth factor system during uterine involution in the postpartum dairy cow. Domest. Anim. Endocrinol. 34:391-402. https://doi.org/10 .1016/j.domaniend.2007.11.003.

Medzhitov, R. 2008. Origin and physiological roles of inflammation. Nature 454:428-435. https://doi.org/10.1038/nature07201.

Mendonça, L. G., N. B. Litherland, M. C. Lucy, D. H. Keisler, M. A. Ballou, L. B. Hansen, and R. C. Chebel. 2013. Comparison of innate immune responses and somatotropic axis components of Holstein and Montbeliarde-sired crossbred dairy cows during the transition period. J. Dairy Sci. 96:3588-3598. https://doi.org/10 $.3168 /$ jds.2012-5804.

Moore, S. G., A. C. Ericsson, S. E. Poock, P. Melendez, and M. C. Lucy. 2017. Hot topic: 16S rRNA gene sequencing reveals the microbiome of the virgin and pregnant bovine uterus. J. Dairy Sci. 100:4953-4960. https://doi.org/10.3168/jds.2017-12592.

Noakes, D. E., L. Wallace, and G. R. Smith. 1991. Bacterial flora of the uterus of cows after calving on two hygienically contrasting farms. Vet. Rec. 128:440-442. https://doi.org/10.1136/vr.128.19 440.

Noleto, P. G., J. P. Saut, and I. M. Sheldon. 2017. Short communication: Glutamine modulates inflammatory responses to lipopolysaccharide in ex vivo bovine endometrium. J. Dairy Sci. 100:22072212. https://doi.org/10.3168/jds.2016-12023.

O'Neill, L. A., R. J. Kishton, and J. Rathmell. 2016. A guide to immunometabolism for immunologists. Nat. Rev. Immunol. 16:553-565. https://doi.org/10.1038/nri.2016.70.

Olive, A. J., and C. M. Sassetti. 2016. Metabolic crosstalk between host and pathogen: Sensing, adapting and competing. Nat. Rev. Microbiol. 14:221-234. https://doi.org/10.1038/nrmicro.2016.12.

Preta, G., V. Lotti, J. G. Cronin, and I. M. Sheldon. 2015. Protective role of the dynamin inhibitor Dynasore against the cholesteroldependent cytolysin of Trueperella pyogenes. FASEB J. 29:15161528. https://doi.org/10.1096/fj.14-265207.

Saut, J. P., G. D. Healey, A. M. Borges, and I. M. Sheldon. 2014. Ovarian steroids do not impact bovine endometrial cytokine/chemokine responses to E. coli or LPS in vitro. Reproduction 148:593-606. https://doi.org/10.1530/REP-14-0230.

Saxton, R. A., and D. M. Sabatini. 2017. mTOR signaling in growth, metabolism, and disease. Cell 168:960-976. https://doi.org/10 $.1016 /$ j.cell.2017.02.004.

Sepúlveda-Varas, P., D. M. Weary, M. Noro, and M. A. von Keyserlingk. 2015. Transition diseases in grazing dairy cows are related to serum cholesterol and other analytes. PLoS One 10:e0122317. https://doi.org/10.1371/journal.pone.0122317. 
Sheldon, I. M., J. Cronin, L. Goetze, G. Donofrio, and H. J. Schuberth. 2009. Defining postpartum uterine disease and the mechanisms of infection and immunity in the female reproductive tract in cattle. Biol. Reprod. 81:1025-1032. https://doi.org/10.1095/biolreprod .109.077370.

Sheldon, I. M., D. E. Noakes, A. N. Rycroft, and H. Dobson. 2004. Effect of intrauterine administration of oestradiol on postpartum uterine bacterial infection in cattle. Anim. Reprod. Sci. 81:13-23. /https://doi.org/10.1016/j.anireprosci.2003.08.010.

Sheldon, I. M., D. E. Noakes, A. N. Rycroft, D. U. Pfeiffer, and H. Dobson. 2002. Influence of uterine bacterial contamination after parturition on ovarian dominant follicle selection and follicle growth and function in cattle. Reproduction 123:837-845. https:// doi.org/10.1530/rep.0.1230837.

Sheldon, I. M., S. E. Owens, and M. L. Turner. 2017. Innate immunity and the sensing of infection, damage and danger in the female genital tract. J. Reprod. Immunol. 119:67-73. https://doi.org/10 .1016/j.jri.2016.07.002.

Sheldon, I. M., A. N. Rycroft, B. Dogan, M. Craven, J. J. Bromfield, A. Chandler, M. H. Roberts, S. B. Price, R. O. Gilbert, and K. W. Simpson. 2010. Specific strains of Escherichia coli are pathogenic for the endometrium of cattle and cause pelvic inflammatory disease in cattle and mice. PLoS One 5:e9192. https://doi.org/10 .1371/journal.pone.0009192.

Sordillo, L. M., G. A. Contreras, and S. L. Aitken. 2009. Metabolic factors affecting the inflammatory response of periparturient dairy cows. Anim. Health Res. Rev. 10:53-63. https://doi.org/10.1017/ S1466252309990016.

Tannahill, G. M., A. M. Curtis, J. Adamik, E. M. Palsson-McDermott, A. F. McGettrick, G. Goel, C. Frezza, N. J. Bernard, B. Kelly, N. H. Foley, L. Zheng, A. Gardet, Z. Tong, S. S. Jany, S. C. Corr, M. Haneklaus, B. E. Caffrey, K. Pierce, S. Walmsley, F. C. Beasley, E. Cummins, V. Nizet, M. Whyte, C. T. Taylor, H. Lin, S. L. Masters, E. Gottlieb, V. P. Kelly, C. Clish, P. E. Auron, R. J. Xavier, and L. A. O'Neill. 2013. Succinate is an inflammatory signal that induces IL-1beta through HIF-1alpha. Nature 496:238-242. https://doi.org/10.1038/nature11986.

Turner, M. L., J. C. Cronin, G. D. Healey, and I. M. Sheldon. 2014 Epithelial and stromal cells of bovine endometrium have roles in innate immunity and initiate inflammatory responses to bacterial lipopeptides in vitro via Toll-like receptors TLR2, TLR1 and TLR6. Endocrinology 155:1453-1465. https://doi.org/10.1210/en .2013-1822.

Turner, M. L., J. G. Cronin, P. G. Noleto, and I. M. Sheldon. 2016. Glucose availability and AMP-activated protein kinase link en- ergy metabolism and innate immunity in the bovine endometrium. PLoS One 11:e0151416. https://doi.org/10.1371/journal.pone .0151416 .

Wathes, D. C. 2012. Mechanisms linking metabolic status and disease with reproductive outcome in the dairy cow. Reprod. Domest. Anim. 47(Suppl. 4):304-312. https://doi.org/10.1111/j.1439-0531 .2012.02090.x.

Wathes, D. C., Z. Cheng, W. Chowdhury, M. A. Fenwick, R. Fitzpatrick, D. G. Morris, J. Patton, and J. J. Murphy. 2009. Negative energy balance alters global gene expression and immune responses in the uterus of postpartum dairy cows. Physiol. Genomics 39:1-13. https://doi.org/10.1152/physiolgenomics.00064.2009.

Wathes, D. C.. Z. Cheng, M. A. Fenwick, R. Fitzpatrick, and J. Patton. 2011. Influence of energy balance on the somatotrophic axis and matrix metalloproteinase expression in the endometrium of the postpartum dairy cow. Reproduction 141:269-281. https://doi .org/10.1530/REP-10-0177.

Wathes, D. C., A. M. Clempson, and G. E. Pollott. 2012. Association between lipid metabolism and fertility in the dairy cow. Reprod. Fertil. Dev. 25:48-61. https://doi.org/10.1071/RD12272.

Wellen, K. E., C. Lu, A. Mancuso, J. M. Lemons, M. Ryczko, J. W Dennis, J. D. Rabinowitz, H. A. Coller, and C. B. Thompson. 2010. The hexosamine biosynthetic pathway couples growth factor-induced glutamine uptake to glucose metabolism. Genes Dev 24:2784-2799. https://doi.org/10.1101/gad.1985910.

Williams, C., J. Brewer, and A. Patton. 1984. The metabolic challenge of the marathon. Br. J. Sports Med. 18:244-252. /https://doi.org/ 10.1136/bjsm.18.4.244

Wittrock, J. M., K. L. Proudfoot, D. M. Weary, and M. A. von Keyserlingk. 2011. Short communication: Metritis affects milk production and cull rate of Holstein multiparous and primiparous dairy cows differently. J. Dairy Sci. 94:2408-2412. https://doi.org/10.3168/ jds.2010-3697.

Zhang, J., N. N. Pavlova, and C. B. Thompson. 2017. Cancer cel metabolism: The essential role of the nonessential amino acid, glutamine. EMBO J. 36:1302-1315. https://doi.org/10.15252/embj .201696151

Zoncu, R., A. Efeyan, and D. M. Sabatini. 2011. mTOR: From growth signal integration to cancer, diabetes and ageing. Nat. Rev. Mol. Cell Biol. 12:21-35. https://doi.org/10.1038/nrm3025.

Zwald, N. R., K. A. Weigel, Y. M. Chang, R. D. Welper, and J. S. Clay. 2004. Genetic selection for health traits using producerrecorded data. I. Incidence rates, heritability estimates, and sire breeding values. J. Dairy Sci. 87:4287-4294. 